\title{
La Banca Cooperativa en México
}

\author{
Jesús Hurtado Maldonado y \\ Graciela Lara Gómez ${ }^{1}$ \\ Universidad Autónoma de Querétaro
}

Sumario: Introducción. I. Disposiciones Generales. II. Aproximación teórica a la banca cooperativa. 2.1. La banca cooperativa: definición y características. 2.2. Antecedentes de la banca cooperativa. III. La banca cooperativa en México. 3.1. Algunos antecedentes. 3.2. Las cajas populares y las cooperativas. 3.3. Nace la banca social. 3.4. La banca social en la cuarta transformación. 3.5. Consideraciones finales. IV. Conclusiones. V. Bibliografía. VI. Anexo legislativo.

Resumen. Con este trabajo se buscó conocer cuál ha sido el avance y presencia de la banca cooperativa en México. Para tal efecto, se realizó una aproximación teórica y un análisis histórico sobre la banca cooperativa y la banca social en el contexto europeo y americano, enfatizando la trayectoria que se ha mantenido en la realidad mexicana, para luego hacer una revisión de los ordenamientos jurídicos que dieron origen a las cooperativas y otras figuras jurídicas similares desde finales del siglo xIx y hasta la actualidad. Los resultados muestran que la banca cooperativa tuvo vida legal en diferentes épocas y que su existencia estuvo vinculada con la política vigente en la administración federal en turno. Se pudo establecer que en la legislación cooperativa de 1994 se preveía la existencia de un banco cooperativo, disposición que posteriormente fue derogada, dando paso a nuevas estrategias del Estado para tratar de resolver la problemática de inclusión financiera.

Palabras clave: Banca, cooperativas, legislación.

Abstract. In this work analyze the progress and presence of cooperative banking in Mexico. For this purpose, a theoretical approach and a historical analysis was carried out on cooperative banking and social banking in the European and American context, emphasizing the trajectory that has been maintained in the Mexican reality, and then making a review of the legal systems

1 Doctores y Profesores-Investigadores de tiempo completo Universidad Autónoma de Querétaro. 
that impulse the cooperatives and other similar legal figures from the end of the 19th century until today. The results show that cooperative banking had a legal life at different times and that its existence was linked to the current policy of the federal administration in turn. It was established that the cooperative legislation of 1994 provided for the existence of a cooperative bank, a provision that was later repealed, giving way to new State strategies to try to solve the problem of financial inclusion.

Keywords: Banking, cooperatives, legislation. 


\section{Introducción}

En los contextos globales y en las realidades locales se requiere de sistemas financieros sanos, que incentiven las actividades productivas y de consumo, para desarrollar económicamente a las naciones, proporcionando los instrumentos de ahorro, crédito e inversión necesarios para facilitar el acceso a aquellos que requieren colocar sus recursos y para los que necesitan de financiamiento. Es evidente que los países y sus sistemas financieros son ampliamente heterogéneos, lo que está marcado por factores externos como las crisis internacionales, pero también por componentes internos, como la forma de gobierno, la legislación, la estructuración del propio sistema financiero, los mecanismos de supervisión y vigilancia, entre otros factores de igual importancia.

El sistema financiero en México y el mundo, se integra por instituciones que ofrecen diversos instrumentos en los mercados; entre las instituciones se encuentra la Banca Cooperativa o también llamada Banca Social, que nace de la necesidad de incluir financieramente a las personas que no son atendidas por la banca comercial.

Este capítulo tiene como objetivo, conocer el avance que ha tenido la banca cooperativa en México. Para tal efecto, desde una aproximación histórica-lógica se aborda el objeto de estudio, para conocer su evolución en tiempo, sus tendencias y características actuales. Luego se efectúa una revisión teórica sobre la banca cooperativa y social en Europa y América, para después entrar al estudio en la realidad mexicana, dando cuenta de los aciertos y desaciertos en la trayectoria legislativa.

Los resultados evidencian, que en las diferentes épocas analizadas prevaleció en México una banca cooperativa -ahora banca socialdébil, dado que no se contó con el apoyo decidido del gobierno para fortalecer a las cooperativas con el reconocimiento legal que les hacía falta e integrar los bancos cooperativos que preveía la legislación cooperativa vigente en 1994.

\section{Aproximación teórica a la banca cooperativa}

En este apartado se explica qué es la banca cooperativa, sus diferentes acepciones y características. Además se hace una breve remembranza histórica, sobre el origen de los bancos cooperativos y su difusión por el mundo. 


\subsection{La banca cooperativa: definición y características}

Diversas acepciones pueden ubicarse en la literatura sobre el tema, que hacen referencia a la banca cooperativa, banca social, banca mutual, banca social no lucrativa, banca sin fines de lucro, banca ética, entre otras que refieren a entidades que forman parte del sistema financiero en sus respectivos países y que tienen un enfoque centrado en la solución de problemáticas financieras de los miembros de una comunidad.

Desde la visión española, Ricardo Javier Palomo Zurdo propone sobre la banca cooperativa que: "puede entenderse como una denominación común, que identifica tanto a las sociedades cooperativas de crédito como a los denominados bancos cooperativos centrales y otras empresas financieras con actividad especializada, que son promovidas y orientadas por las cooperativas de crédito» (1).

Para Guillermo Westreicher, la banca cooperativa significa «el segmento del sistema financiero que agrupa a cooperativas de ahorro y crédito, bancos cooperativos centrales y otras entidades similares. Dichas empresas buscan un mayor acercamiento y entendimiento del cliente que el de la banca comercial» (1). Cabe señalar que la expresión común entre el sector cooperativo es socio o asociado, aunque en algunas sociedades también se presta servicio a no asociados a los que puede denominarse cliente.

Los autores Joan Ramón Sanchis y Enrique Pascual García advierten algunas diferencias entre los bancos cooperativos y los bancos éticos, que en conjunto con las entidades de crédito, se consideran como integrantes de una estructura mayor: la banca social. De manera que, los bancos cooperativos existen hace más de un siglo, desarrollando actividades mediante un modelo de banca de proximidad, con enfoque al territorio, mientras que los bancos éticos tienen unas tres décadas de existencia, llevando a cabo proyectos sociales y medioambientales con enfoque en las inversiones socialmente responsables (152).

Por su parte, Carlos Cuevas y Klaus Fischer proponen la denominación 'instituciones financieras cooperativas', para incluir a los intermediarios financieros cuya propiedad está en poder de sus miembros, entre ellas quedan comprendidas las denominadas: cooperativas financieras, cooperativas de crédito, cooperativas de ahorro y crédito, los bancos cooperativos y otras entidades, cuyas denominaciones difieren entre las regiones del mundo (54). También dicen que la expresión banco cooperativo se emplea a menudo, para representar a una institución financiera cooperativa que posee una licencia bancaria (14). 
Las dos visiones mencionadas, tienen puntos de encuentro que ayudan a entender la idea que se tiene de la banca cooperativa, como un participante de una estructura mayor incrustada en el sistema financiero. Desde la perspectiva de Sanchis y Pascual, la banca social integra a los bancos cooperativos, las cooperativas de crédito y a otras entidades. Mientras que Cuevas y Fisher agrupan en las Instituciones Financieras Cooperativas, a las cooperativas, bancos cooperativos y otras entidades (figura 1).
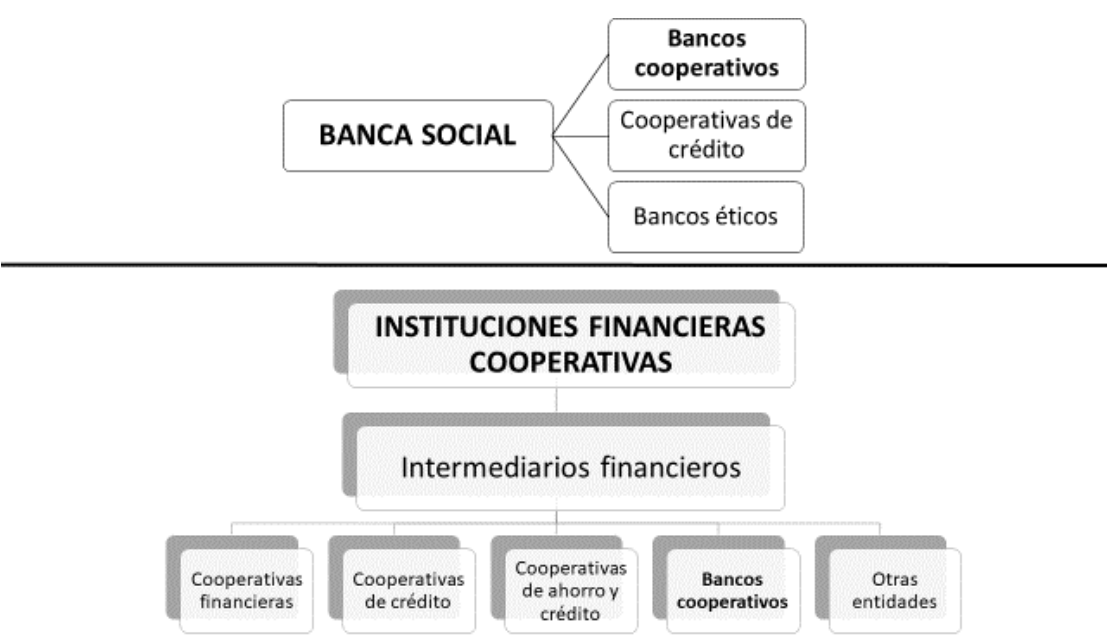

Fuente: Sanchis y Pascual, 2017; Cuevas y Fisher. 2006.

Figura 1

Los bancos cooperativos

De lo anterior se desprende que los diferentes significados son empleados como sinónimos, pero que diversos teóricos se han enfocado a establecer las características y elementos diferenciadores. Entre ellos se encuentra Guillermo Westreicher, quien destaca que existe una clara diferenciación entre el modelo de negocio de los bancos tradicionales y la banca cooperativa, aunque esta última realiza actividades similares, como es la recepción de depósitos, el otorgamiento de préstamos y otros servicios de intermediación financiera. Por lo que son elementos clave en la banca cooperativa, los que atienden al conocimiento del mercado, el arraigo y el involucramiento en la vida comunitaria de sus usuarios (1). 
Por tanto, desde la propuesta de Westreicher, pueden describirse las características básicas de los bancos cooperativos (1).

a) El arraigo, que permite la vinculación de la entidad con el territorio donde se prestan los servicios.

b) El conocimiento del mercado, implica el diseño de productos financieros de acuerdo con las necesidades del usuario del servicio.

c) El involucramiento, que conlleva la vinculación de la entidad en los intereses de los usuarios de los servicios, por ejemplo, apoyando en el establecimiento de redes con posibles socios comerciales o bien a través del patrocinio de actividades de interés para la comunidad.

Por su parte, Carlos Cuevas y Klaus Fischer coinciden con Westreicher en cuanto al objetivo y servicios que se proporcionan. No obstante, indican que existen grandes divergencias entre las entidades cooperativas, debido a los servicios financieros que se proporcionan y que su magnitud varía de acuerdo con su ubicación, ya que pueden operar en países desarrollados y en desarrollo, lo que influye en su estructura, gobernanza institucional, marco legal y regulatorio (54). Para estos autores, existen dos características esenciales de las instituciones financieras cooperativas (74):

- Una característica común es que reciben depósitos, otorgan créditos y hacen negocios casi exclusivamente con los miembros (algunas entidades lo hacen con no socios).

- Sirven a un importante número de personas pobres, aunque también se encuentran usuarios de ingresos medios.

Se ha establecido que los bancos cooperativos pueden ser reconocidos por sus características esenciales que implican, llevar a cabo intermediación financiera con participantes que se encuentran ligados a los bancos, generando lazos de cercanía, identidad y cohesión, tanto a nivel personal como comunitaria.

\subsection{Antecedentes de la banca cooperativa}

Wim Fonteyne retomando a Hasmann señala que el origen de los bancos cooperativos surge en Alemania en los siglos XIX y XX, como consecuencia de la problemática económica que vivía gran parte de la población. En el continente europeo surgen a partir de las ideas de Hermann Shultze (1808-1883) y de Friedrich Wilhelm Raiffeisen (1818-1888), quienes percibían el estado de miseria y escaso acceso al financiamiento, ex- 
cepto por el que se proveía a través de los prestamistas usureros. Schultze, fijó como objetivo ayudar a los dueños de negocios y artesanos, mientras que Raiffeisen se enfocó en la población rural pobre. La banca cooperativa se extendió al resto de Europa y los países nórdicos, aunque las Islas Británicas tienen sus raíces en el movimiento cristiano renacentista; las que surgieron en Reino Unido e Irlanda durante el siglo Xx, están basadas en el las cooperativas de crédito de Estados Unidos y estos a su vez se inspiraron en el movimiento canadiense que inició con las ideas de la propuesta alemana (8).

Rodolfo Rezsohazy, reconoce en el alemán Friedrich Wilhelm Raiffeisen al fundador del cooperativismo de crédito, quien inicia la primera organización de este tipo, cuando logra reunir a un grupo de campesinos pobres, para defenderse de los usureros y generar sus propios mecanismos de financiamiento. La idea fundamental está basada en el autoempleo, de manera que los miembros son los propios banqueros, pero modificando la finalidad de lucro, reduciendo las tasas de interés, básicamente obtener lo necesario para sufragar los gastos (108).

Al respecto, Rodolfo Rezsohazy dice que mientras las cooperativas de crédito se fueron multiplicando en el contexto rural por todo el mundo, en Estados Unidos y Canadá surgían formas de financiamiento para los artesanos y la clase media, las que estaban basadas en los principios centrales de la cooperación (109). No obstante, los esfuerzos para crear bancos cooperativos no solamente emanan de iniciativas de las personas, pues existen evidencias de que los gobiernos han impulsado su inserción en las sociedades. En este sentido, Wim Fonteyne dice que en Francia, Finlandia y Portugal el impulso de los bancos cooperativos correspondió al gobierno, pero también existieron otros actores fundamentales, como la Iglesia católica, cuyo rol fue importante en Francia, Italia y Bélgica. No puede ignorarse que en la formación de tales organizaciones, además se ha tenido la participación de sindicatos y organizaciones agrícolas (8).

Carlos Cuevas y Klaus Fischer explican que las particularidades de las instituciones financieras cooperativas en el contexto global, se remiten a sus raíces históricas continentales, por ejemplo, el modelo europeo que se vincula al Raifeissen o el anglosajón, que alude a las cooperativas de crédito. Además, no puede soslayarse que existieron importantes detonadores que dieron pauta a la introducción de las cooperativas en América, como lo fue el trabajo de los misioneros, los que llegaron antes que las organizaciones internacionales (54).

Desde la visión de Heiko Hesse y Martín Čihák, los bancos cooperativos no han tenido la atención debida en la literatura, sobre todo si se toma en cuenta que estos, se encuentran entre los 25 principales gru- 
pos bancarios de la Unión Europea, en términos de patrimonio consolidado y poseen el 40 por ciento de participación en el mercado, en términos de sucursales (3). No obstante, Wim Fontayne afirma que a pesar del importe grado de madurez de los bancos cooperativos europeos, ahora se enfrentan al dilema de cómo el sector bancario cooperativo debe evolucionar (14).

Rodrigo Mogrovejo, Alberto Mora y Philippe Vanhuynegem señalan que las cooperativas llegan a América Latina en la primera mitad del siglo xIX, en países como Argentina, Brasil, México y Venezuela; mientras que en las primeras décadas del siglo xx se desarrollaron gradualmente en el resto de los países. La fundación de tales organizaciones se concretó, gracias a la influencia de inmigrantes europeos en Sudamérica quienes participaron en la promoción de cooperativas de consumo, de tipo financiero y cajas de socorro mutuo. Un papel relevante fue el que le correspondió a la Iglesia católica, institución que influyó fuertemente en los países de la región andina, en México y Centroamérica. Además, en algunos países la creación de las cooperativas estuvo a cargo de los gobiernos y en su fundación también intervinieron los sindicatos (13).

El autor, Jorge Coque Martínez coincide en señalar que el cooperativismo moderno en América Latina fue impulsado por tres actores principales: los emigrantes europeos, la iglesia católica y los gobiernos nacionales; sobre los segundos, destaca la participación de la iglesia católica a través de la doctrina social, cuya experiencia en Antigonish Nueva Escocia, Canadá, fue de especial relevancia por las técnicas de educación popular que promovió el desarrollo regional entre la comunidad de pescadores (153).

Carlos Pineda indica que por lo que toca a las cooperativas en Estados Unidos y Canadá, puede comentarse que el cooperativismo financiero llega a esta región en la última década del siglo XIX y los primeros del siglo Xx. Uno de los movimiento más importantes en Norteamérica fue fundado por Alphonse Desjardins), quien tomando las ideas del cooperativismo europeo, creó la primera caisse populaire (caja popular) entre 1900 y 1906 en Quebec, Canadá. Años después, a invitación de Monseñor Hevea, Desjardins viaja a Manchester, New Hampshire y funda la primera caja popular en Estados Unidos, la que toma el nombre de credit union. Las cooperativas en Estados Unidos fueron promovidas por Eduardo A. Filene, Pierre Jay y Roy F. Bergengren (1). Actualmente, las caisses populaires y las credit union son entidades financieras cooperativas muy influyentes en sus respectivos países.

En consecuencia, la organización, legislación y en general en funcionamiento de la banca cooperativa en el contexto mundial es sumamente heterogéneo, dado que se encuentra integrada por organi- 
zaciones estables y maduras (como la banca cooperativa Europea y la establecida en América del Norte) y otras que tienen un bajo grado de sofisticación y estabilidad (como la banca en América Latina).

\section{La banca cooperativa en México}

En este apartado se abordan los antecedentes legislativos del sistema financiero y la banca cooperativa en México, discutiendo los aportes, aciertos y desaciertos del Estado en las estrategias para crear y mantener una banca social activa y funcional. También se aborda sobre el nacimiento de las cajas populares, su trayectoria y avance para su legislación.

\subsection{Algunos antecedentes}

Para comprender el avance y trascendencia de la banca cooperativa en México, es necesario identificar los ordenamientos jurídicos que dan vida legal a las cooperativas desde finales del siglo XIX y hasta la actualidad. De manera que, en durante el periodo en que el General Porfirio Díaz se desempeñaba como Presidente de la República (1877- 1910), se publicó el 15 de septiembre de 1889 el Código de Comercio, cuya entrada en vigor fue el $1 .^{\circ}$ de enero de 1890. Precisamente, en el Título Segundo. De las Sociedades de Comercio, Capítulo I, se incluyó a la sociedad cooperativa como una sociedad mercantil (Código de Comercio, 15).

Posterior al triunfo de la Revolución y la promulgación de la Constitución de 1917, en México fueron publicados en diversas épocas, cuatro ordenamientos legales para las cooperativas. La primera legislación surge en 1927, la segunda en 1933, mientras que la tercera en 1938 y la legislación vigente fue publicada en 1994. Debe indicarse que la condición de sociedad mercantil atribuida a las cooperativas ha persistido hasta la actualidad, lo que se confirmó con publicación en la Ley General de Sociedades Mercantiles del 4 de agosto de 1934 (593), donde se tomaron las sociedades mercantiles que antes estaban contenidas en el Código de Comercio de 1889 y que ahora se integran en la legislación mercantil vigente, conservando a las sociedades cooperativas he incluyendo el Capítulo VII con un único artículo, el 212, que en su norma original dice: "Las sociedades cooperativas se regirán por su legislación especial» (Ley General de Sociedades Mercantiles, 1934). 
Previo a la publicación de la primera legislación específica para las cooperativas y ya en el periodo posrevolucionario, el presidente constitucional Plutarco Elías Calles, promulgó la Ley de Instituciones de Crédito y Establecimientos Bancarios el 24 de diciembre de 1924, abrogando la Ley General de Instituciones de Crédito del 13 de marzo de 1987 (817). Con este acto legislativo se retoma la regulación para la deteriorada actividad financiera en el país.

En este sentido, Javier Márquez que posterior a la publicación de la Ley de Instituciones de Crédito y Establecimientos Bancarios, en las décadas subsecuentes se emitieron nuevas leyes y reglamentos para regular al sistema financiero y sus instituciones, privilegiando la banca privada especializada y al control selectivo del crédito. Entre las instituciones que surgen en épocas posteriores, destaca la aparición entre 1946 y 1947 de los Bancos de Ahorro y Préstamo para la Vivienda Popular, cuya desaparición ocurre en 1970 (1894).

En los años posteriores, se crearon diversos bancos de apoyo a los sectores más desprotegidos, como el Banco Obrero, el Banco del Pequeño Comercio (Adalberto Emilio Pimentel, 123). Particularmente, la banca cooperativa aparece en México durante las primeras décadas del siglo XX, debido a las acciones instrumentadas desde el Estado y que tenían como objetivo, dar servicio financiero a las cooperativas de esa época. El 5 de junio de 1941 se crea el Banco Nacional de Fomento Cooperativo, S. A. de C. V., que estaría dedicado a apoyar el ahorro, el crédito hipotecario, financiero y fiduciario; se le fijó como objetivo primordial, actuar como fiduciaria sobre los bienes y derechos del gobierno federal y estatal, así como de las cooperativas, uniones de crédito popular, dar servicio a los particulares, entre otras (Adalberto Emilio Pimentel, 123).

Algunas décadas después, precisamente el 31 de diciembre de 1979 se publica en el Diario Oficial de la Federación, la Ley Orgánica del Banco Nacional Pesquero y Portuario, S. A., que cambia la denominación del Banco Nacional de Fomento Cooperativo, S. A. de C. V., por el de Banco Nacional Pesquero y Portuario. En la ley se establece en su artículo 5, que el objeto del Banco será la promoción y financiamiento para las actividades de pesca, portuarias y navieras, con la intervención de instituciones de crédito y sociedades cooperativas del ramo (1).

La finalidad de las instituciones bancarias antes mencionadas, tuvo como objeto el financiamiento a las cooperativas en general y luego con la modificación de su denominación, los servicios financieros fueron dirigidos al sector pesquero. Debe señalarse que, ambas instituciones siempre fueron controladas por el Estado, por lo que no se contempló la participación directa del sector cooperativo. 


\subsection{Las cajas populares y las cooperativas}

A mediados del siglo xx llegaron las cajas populares, las que toman su nombre de las caisses populaires de Canadá y que fueron introducidas por la iglesia católica, cuando en 1949 a través del Secretariado Social Mexicano, el sacerdote católico Pedro Velázquez promovió una beca en la Universidad de San Francisco Xavier, en Antigonish, Nueva Escocia, Canadá que benefició a los sacerdotes Carlos Talavera y Manuel Velázquez. El objetivo de los sacerdotes era aprender la filosofía y práctica del cooperativismo canadiense, pero también conocieron las credit union de Estados Unidos. Cuando los sacerdotes Talavera y Velázquez regresaron a México, junto con Manuel Velázquez, cristalizaron lo aprendido a través del importante movimiento de cajas populares que benefició a sectores empobrecidos de la población. La primera caja popular se fundó el 12 de octubre de 1951 y se denominó Caja Popular León XIII, luego siguieron la Caja San Simón, la Caja Popular Lorenzo Robles y otras más que se crearon en barrios pobres del entonces Distrito Federal (Florencio Eguía, 23).

La fecha que se designó como la fundación del movimiento de cajas populares fue precisamente 12 de octubre de 1951, que correspondía a la creación de la primera organización de este tipo (Eguía, 23). A este respecto, Graciela Lara señala que en esa época no existían ordenamientos jurídicos que sustentarán la intermediación financiera de las cajas populares, por lo que se integraron pretendiendo ser cooperativas, sin una figura jurídica propia, sin el apoyo de las autoridades, pero siempre basando su actuar en la confianza. Para 1955, con la intervención de sacerdotes católicos que se sumaron al movimiento, se crearon un número importante de cajas populares que funcionaban con el apoyo de los propios socios, ya para 1964 se inició un proceso de estructuración piramidal, creando una confederación y varias federaciones estatales (20-21).

Luego de décadas de esfuerzos para que el Estado legitimara la función financiera de las cajas populares, entre 1986 y 1987 se logró su reconocimiento legal en ordenamientos locales vigentes en Querétaro y Zacatecas, lo que no fue suficiente, dado que la facultad legislativa en materia de intermediación financiera es exclusiva del Congreso de la Unión y no de las legislaturas locales. Al poco tiempo, en 1991 se reforma la Ley General de Organizaciones y Actividades Auxiliares del Crédito, que crea a la Sociedad de Ahorro y Préstamo, con la que se pretendió dar personalidad jurídica a las cajas populares; como consecuencia, las dos leyes locales fueron abrogadas (Graciela Lara, 57). 
Ante el fracaso del primer intento por regular las actividades de las cajas populares, que llevó a la constitución de unas pocas sociedades de ahorro y préstamo, se suscitaron diversos eventos históricos a partir de 1994, los que marcaron la existencia legal de las cooperativas y concretamente de las cooperativas de ahorro y préstamo.

Con la Ley General de Sociedades Cooperativas, dada a conocer en el Diario Oficial de la Federación de fecha 3 de agosto de $1994^{2}$ y que entró en vigor 30 días posteriores a su publicación, inicia una nueva época en la que por primera vez se reconoce la actividad de ahorro y préstamo como propia de las cooperativas. De manera que, se establece que las cooperativas de consumidores podrían llevar a cabo actividades de ahorro y préstamo (artículo 26: 23). Una disposición relevante fue la incluida en la artículo 87 (30), donde se establecía que las cooperativas con actividad de ahorro y préstamo, podrían integrar uniones de crédito y bancos de fomento cooperativo.

Cabe señalar que dicha ley fue un parteaguas para las cajas populares, pero también un gran obstáculo, ya que con su publicación inició un importante registro de cooperativas, aunque no todas con esencia centrada en la filosofía de la cooperación, lo que luego condujo a escandalosos fraudes. La legislación presentaba diversas debilidades, como la ausencia de infracciones y sanciones, además de que se dejaba en los administradores de las cooperativas, determinar la forma de operación, administración y vigilancia. Debe decirse que el artículo 87, realmente fue inoperante, ya que nunca se emitieron disposiciones en las leyes financieras, para la creación de bancos de fomento cooperativo.

Graciela Lara afirma que ante las múltiples carencias de la nueva legislación cooperativa, entre 1996 y 1999, líderes del sector insistieron ante la Secretaría de Hacienda y Crédito Público, la Comisión Nacional Bancaria y de Valores y otras instancias gubernamentales, para que intervinieran en la vigilancia de las cooperativas con actividades financieras, lo que derivó en que en $2001^{3}$ se publicará la Ley de Ahorro y Crédito Popular, con la que se regularía la intermediación financiera de las cooperativas; al mismo tiempo se reformó la Ley General de Socieda-

2 Fue en el sexenio de Carlos Salinas de Gortari donde se modificó la Ley General de Organizaciones y Actividades Auxiliares del Crédito y fue publicada la Ley General de Sociedades Cooperativas, lo que trajo como consecuencia la abrogación de la ley cooperativa de 1938,

3 La Ley de Ahorro y Crédito Popular se publicó durante el sexenio de Vicente Fox Quesada (2000-2006). Dicho ordenamiento jurídico, no resolvió la problemática de control y vigilancia para el sector cooperativo, por el contrario, abrió grandes brechas entre los participantes en el sector de ahorro y crédito popular, pues existía un grupo que opuso una tenaz resistencia para acatar las normas. 
des Cooperativas, para incluir junto a las cooperativas de productores y consumidores, a las de ahorro y préstamo (58).

\subsection{Nace la banca social}

Con la reforma a la Ley General de Sociedades Cooperativas del 4 de junio de 2001, se derogaron diversas disposiciones, entre ellos el artículo 87, que permitía la creación de bancos de fomento cooperativo (artículo Tercero, Decreto: 90). Con dicha derogación se iniciaron acciones por parte del Gobierno Federal para integrar una institución bancaria que se vinculara con las cooperativas de ahorro y préstamo, a efecto de proporcionarles servicios financieros. Es por ello que, el 29 de noviembre de 2001, se publicó el Decreto de transformación del Patronato del Ahorro Nacional en el Banco del Ahorro Nacional y Servicios Financieros, Sociedad Nacional de Crédito (Bansefi). Con la nueva orientación de Bansefi, se pretendía llevar a cabo la prestación de servicios de banca y crédito y de banca de desarrollo, con lo que se apoyarían las políticas de desarrollo nacional, particularmente del sector de ahorro y crédito popular ${ }^{4}$ (SACP).

Es un hecho que el Bansefi desempeñó un rol preponderante en las políticas de desarrollo del sector, las que ya se habían contemplado en el Plan Nacional de Desarrollo del presidente Vicente Fox, donde se incorpora la expresión banca social, para dar idea de una institución dirigida a los sectores rurales y zonas urbanas marginadas que habitualmente no habían tenido acceso a los beneficios del desarrollo. La novedosa banca social tendría dos ejes esenciales: el primero sería, ordenar a través de un marco normativo de supervisión y criterios contables similares a los del resto de los intermediarios financieros. Mientras que el segundo, estimularía proyectos viables, a través de microcréditos dirigidos a emprendedores mexicanos, principalmente con enfoque para los sectores más desprotegidos (Plan Nacional de Desarrollo, 104).

Junto con el sector de ahorro y crédito popular, en el Bansefi a partir de 2002, se iniciaron importantes acciones, donde se incluyó la participación de organismos internacionales, especializados en bancos cooperativos y cooperativismo financiero. Graciela Lara (105) dice que entre las acciones que llevaron a cabo a través de la novedosa banca

4 El sector de ahorro y crédito popular está integrado por las organizaciones del sector cooperativo y las Sociedades Financieras Populares, entidades concebidas en la Ley de Ahorro y Crédito Popular. 
social, se pusieron en marcha 6 programas de apoyo al SFP, los cuales fueron:

- Asistencia técnica. Se dirigió a la creación de planes y programas de trabajo para el sector. Este proyecto fue apoyado por organismos internacionales especializados en banca cooperativa.

- Capacitación. Buscó la profesionalización del personal y directivos del SACP.

- Plataforma tecnológica. Se concentró en el diseño y desarrollo de infraestructura tecnología para el sector y Bansefi.

- La red de la gente. Consistió en una alianza comercial con el SACP.

- Campaña de difusión. Su enfoque fue dar a conocer el nuevo proceso al que se sujetaría el SCAP.

- Otros apoyos. Básicamente este programa se enfocó a: estudios de evaluación y monitoreo, fortalecimiento de la capacidad de supervisión y apoyo a organismos de integración.

Cabe puntualizar que se sentaron las bases para crear la L@Red de la Gente, que fue uno de los proyectos más importantes creados por el banco social y que ha trascendido hasta la actualidad. El programa mencionado, se visualizó como una alianza comercial entre Bansefi e integrantes del SACP, para dar servicio en zonas rurales y semi urbanas no atendidas por la banca tradicional a la población excluida de servicios financieros, entre otros, el pago de envíos de dinero a través de remesas internacionales, remesas nacionales, microseguros y recepción de pagos (Anuario Financiero de la Banca en México, 12).

Por tanto, las acciones que se ejecutaron desde el inicio de la existencia de Bansefi fueron: la profesionalización de los gerentes y directivos en conocimientos sobre administración y finanzas, certificar a los comités de supervisión auxiliar, lograr las autorizaciones de la Comisión Nacional Bancaria y de Valores para las cooperativas, así como vincular las operaciones financieras del sector con el banco.

De manera que las acciones llevadas a cabo a través del Bansefi, estuvieron marcadas por divisiones e inconformidades por parte de los dirigentes de las cooperativas y organismos de integración, así como de algunos desaciertos que determinarían el futuro del SACP.

Por lo mencionado puede afirmarse que, las políticas instrumentadas durante el sexenio presidencial 2000-2006, se acertó en que era necesaria la institucionalización del sector, pero desafortunadamente las constantes pugnas condujeron un importante dispendio de recursos y a que durante el siguiente sexenio presidencial, fueran derogadas las disposiciones para las cooperativas, contenidas en la Ley de Ahorro y Crédito Popular. 
Entre 2006 y 2009, el único evento relevante fue la publicación en 2009 de Ley para Regular las Actividades de las Sociedades Cooperativas de Ahorro y Préstamo, la que actualmente sigue vigente ${ }^{5}$. Es necesario señalar que durante el sexenio que transcurrió entre 2012-2018, no surgieron eventos legislativos que tuvieran trascendencia para la banca social.

\subsection{La banca social en la cuarta transformación en México}

En el Plan Nacional de Desarrollo 2019-2024 se incluyó como uno de los objetivos, la creación del Banco del Bienestar, que sustituiría al Bansefi. El propósito principal sería brindar servicios bancarios a los beneficiarios de programas sociales, para lo que se ampliaría la infraestructura con 500 sucursales, hasta alcanzar siete mil en todo el territorio mexicano Plan Nacional de Desarrollo, 52).

Como parte de las acciones del actual gobierno Federal que inició en 2018, se instrumentaron acciones que derivaron en la publicación del Decreto por el que se reforman y adicionan diversas disposiciones de la Ley Orgánica del Banco del Ahorro Nacional y Servicios Financieros de fecha 19 de julio de 2019, con el que principalmente se buscó el cambio de denominación del Bansefi al Banco del Bienestar, Sociedad Nacional de Crédito, estableciendo que realizará funciones de banca social, manteniendo en gran medida el objeto social que se había venido desarrollando. En el apartado del Diario de Debates se expuso que los productos y servicios estarían dirigidos a la población de menores ingresos, favoreciendo a los que se encuentran en estados de vulnerabilidad, exclusión, discapacidad, marginación o discriminación con lo que se espera la reducción del desempleo, violencia e inestabilidad social (Decreto, 2).

Sobre los recientes cambios, todavía es muy temprano para evaluar si las acciones que se llevarán a cabo a través del Banco del Bienestar, favorecerán el desarrollo y fortalecimiento del SACP.

\subsection{Consideraciones finales}

La organización, legislación y en general en funcionamiento de la banca cooperativa en el contexto mundial es sumamente heterogéneo,

5 La Ley para Regular las Actividades de las Sociedades Cooperativas de Ahorro y Préstamo, fue publicada durante el sexenio 2006-2012, del presidente Felipe Calderón Hinojosa. 
dado que se encuentra integrada por organizaciones estables y maduras (como la banca cooperativa Europea y la establecida en América del Norte) y otras que tienen un bajo grado de sofisticación y estabilidad (como la banca en América Latina).

En México puede observarse una banca cooperativa que corresponde a las características que se le atribuye a las instituciones latinoamericanas, dado que a través de la historia se han constatado los altibajos y la debilidad en las políticas públicas para alentar su consolidación. Pudo establecerse que la banca cooperativa ha estado presente en la realidad nacional desde 1941, con el Banco Nacional de Fomento Cooperativo, S. A. de C. V., luego en la legislación cooperativa de 1994 y después, desde 2001 a la fecha, se introdujo la expresión banca social, para designar a la institución bancaria que ha estado a cargo de los proyectos de inclusión financiera, donde participan activamente los intermediarios del SACP. Cabe mencionar que solamente se ha modificado la denominación de dicho banco —antes Bansefi, ahora Banco del Bienestar-y se ha conservado el objetivo y algunos programas (figura 2).

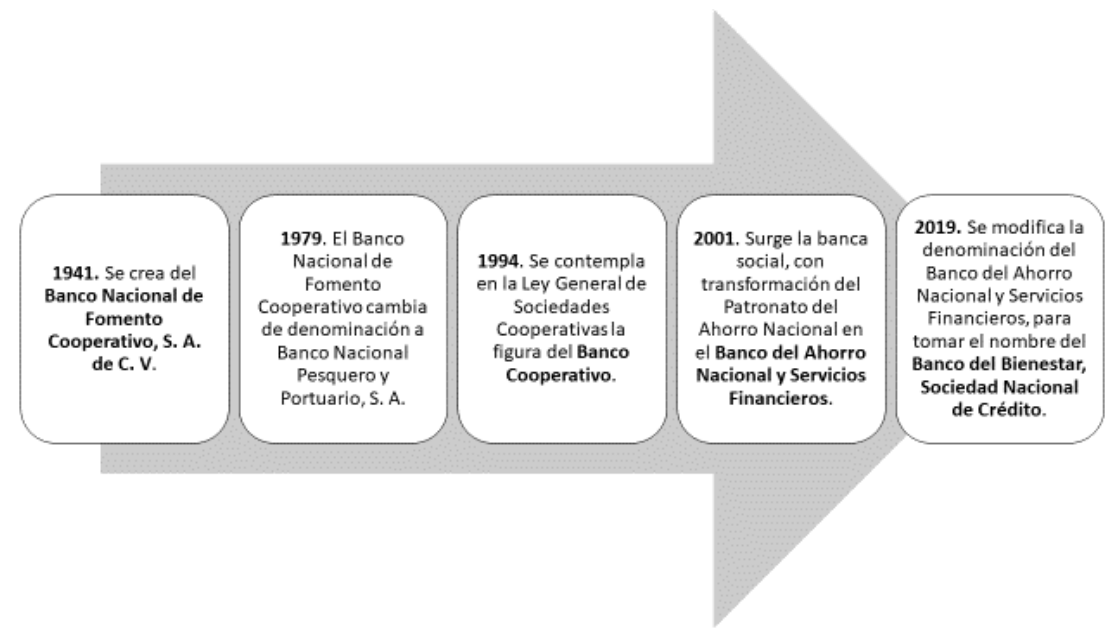

Fuente: elaboración propia.

Figura 2

Cronología de la banca cooperativa en México 
Ha sido evidente que durante décadas se ha dejado en el olvido a las cooperativas de ahorro y préstamo, pues transcurrieron 40 años para que estas contaran con una legislación federal que reconociera sus actividades y que las dotara de personalidad jurídica propia. Con la publicación de la Ley General de Sociedades Cooperativas de 1994, se buscó su reconocimiento legal y se abrió la posibilidad de crear un Banco cooperativo que funcionara con apego a principios y valores de la cooperación, pero eso no fue posible, debido entre otras cosas, a la propia debilidad del ordenamiento, el que fue formulado con poca diligencia y sin considerar las necesidades reales del sector.

Con los argumentos que se han presentado, puede decirse que en México la Banca cooperativa o banca social, se ha concebido como una institución del sistema financiero creada por el Estado, con la finalidad de que a través de ella, se proporcionen servicios y apoyos para las cooperativas de ahorro y préstamo y otros intermediarios financieros dedicados al ahorro y crédito popular. El decreto de creación de la Banca Social, no consideró en ninguna circunstancia, la participación de las entidades del sector, en el capital social del banco, es decir, las cooperativas no pueden tener carácter de socios o accionistas.

Por tanto, es evidente que todavía falta mucho por hacer por parte del Estado y de los sectores interesadas, para realmente cristalizar un proyecto de viable de banca cooperativa en México.

\section{Conclusiones}

Es innegable que cualquier sociedad requiere que los integrantes del sistema financiero no solo se concentren en maximizar sus rendimientos, sino que debe considerarse la incorporación de una banca con enfoque social, que sea cercana a la gente y que represente el apoyo que requieren las cooperativas de ahorro y préstamo para su fortalecimiento, pues no puede ignorarse que hasta la actualidad algunos segmentos de la población se encuentran todavía excluidos de los servicios financieros, por lo que hace falta una estructura financiera, apoyada por el Estado, donde se privilegie la inclusión financiera en los más pobres.

La Banca Social que funciona en México, durante su primera época fue planteada con objetivos claros, de cuya ejecución se obtuvieron algunos logros que se tradujeron en: la incipiente profesionalización de los participantes en el SACP, las autorizaciones para las cooperativas de ahorro y la creación de redes de servicios para el sector y sus usuarios, pero no fue suficiente para conseguir la inclusión financiera que se esperaba. Ahora se ofrece una nueva versión de la Banca Social a través del Banco del Bienestar, se espera que el proyecto del ejecutivo permee entre los 
sectores más desprotegidos. No obstante, se reconoce que todavía es temprano para valorar si la nueva estrategia del gobierno federal será la adecuada para consolidar una institución eficiente, estable y sólida.

\section{Bibliografía}

Anuario Financiero de la Banca en México. Reseña anual 2012, Instituciones bancarias Bansefi, pp. 1-18. Acceso en línea el 21/06/2020.

Coque MARTínez, Jorge. "Las cooperativas en América Latina: visión histórica general y comentario de algunos países tipo». CIRIEC-España, Revista de Economía Pública, Social y Cooperativa, vol., No. 43, 2002, pp. 145-172.

Cuevas, Carlos E., FISCHer, Klaus P. Cooperative Financial Institutions: Issues in Governance, Regulation, and Supervision. World Bank Working Paper n. ${ }^{\circ} 82$, Washington, DC: World Bank. June 2006. Acceso en línea el 12/06/2020.

Eguía V., Florencio. «En Manos del Pueblo». México: Ed. Confederación Mexicana de Cajas Populares, México, 1984, pp. 1-252.

FonTEYNE, Wim. "Co-operative Banks in Europe-Policy Issues». International Monetary Fund (Working Paper) (2007): 1-28. Acceso en línea el 12/06/2020.

HESSE, Heiko \& ČIHÁK, Martín. "Co-operative Banks and Financial Stability». International Monetary Fund (Working Paper) (2007): 1-32. Acceso en línea el 12/06/2020.

LARA G., Graciela. «Cambio organizacional en una federación del Sector Financiero Popular». México: Editorial Plaza y Valdés, 2011, pp. 1-220.

MÁrquez, Javier. La Banca en México: 1830-1983. El Trimestre Económico, Vol. 50, No. 200(4), número especial 50 aniversario (Octubre-Diciembre de 1983), pp. 1873-1914.

Mogrovejo, Rodrigo; Mora, Alberto \& Vanhuynegem, Philippe, Eds. El cooperativismo en América Latina. Una diversidad de contribuciones al desarrollo sostenible. La Paz: OIT, Oficina de la OIT para los Países Andinos, 2012. 400 p.

Palomo ZuRdo, Ricardo Javier. Diccionario Económico. Banca Cooperativa. Expansión.com. En línea. Fecha de acceso 11/06/2020.

Pimentel, Adalberto Emilio. Prácticas Administrativas y Comerciales, 2. ${ }^{a}$ edición, México: Grupo Noriega editores, 1993. Acceso en línea el 19/06/2020.

Pineda Carlos. Las cooperativas en Canadá y Estados Unidos. Noviembre, 2019 Perspectiva-Económica. En línea. Fecha de acceso 16/06/2020.

RezsohazY, Rodolfo. "Los Principios Cooperativos», en Los Principios del Cooperativismo de Rochdale a nuestros días. Florencio Eguía (compilador) 101142. 1991. México: Confederación Mexicana de Cajas Populares.

Sanchiz Palacio, Joan Ramón \& Pascual García, Enrique. "Banca ética y banca cooperativa. Un análisis comparativo a través del estudio de Caixa Popular y de Fiare Banca Ética». REVESCO. Revista De Estudios Cooperativos (2017): 124, 152-174. Acceso en línea el 12/06/2020.

Westrelcher, Guillermo. Banca Social. Economipedia. 2012. Acceso en línea el $12 / 06 / 2020$. 


\section{Anexo legislativo}

- Código de Comercio. Diario Oficial del 15 de septiembre de 1889 (archivos de la Cámara de Diputados). Acceso en línea el 17/06/2020.

- Decreto por el que se expide la Ley de Ahorro y Crédito Popular y se reforman y derogan diversas disposiciones de la Ley General de Organizaciones y Actividades Auxiliares del Crédito y de la Ley General de Sociedades Cooperativas. Diario Oficial de la Federación del 4 de junio de 2001. Acceso en línea el 20/06/2020.

- Decreto por el que se reforman y adicionan diversas disposiciones de la Ley Orgánica del Banco del Ahorro Nacional y Servicios Financieros. Publicado en el Diario Oficial de la Federación el 19 de julio de 2019. Acceso en línea el 21/06/2020.

- Decreto por el que se transforma el Patronato del Ahorro Nacional, Organismo Descentralizado del Gobierno Federal, en el Banco del Ahorro Nacional y Servicios Financieros, Sociedad Nacional de Crédito, Institución de Banca de Desarrollo. Diario Oficial de la Federación del 29 de noviembre de 2001. Acceso en línea el 20/06/2020.

- Ley de Instituciones de Crédito y Establecimientos Bancarios. Diario Oficial del 31 de agosto de 1926 (archivos de la Cámara de Diputados).

- Ley General de Sociedades Mercantiles. Diario Oficial del 4 de agosto de 1934 (archivos de la Cámara de Diputados). Acceso en línea el 17/06/2020.

- Ley Orgánica del Banco Nacional Pesquero y Portuario, S. A. Diario Oficial de la Federación del 31 de diciembre de 1979. Acceso en línea el $18 / 06 / 2020$.

- Plan Nacional de Desarrollo 2001-2006. Gobierno de los Estados Unidos Mexicanos. Presidencia de la República. Acceso en línea el 20/06/2020.

- Plan Nacional de Desarrollo 2019-2024. Gobierno de los Estados Unidos Mexicanos. Presidencia de la República. Acceso en línea el 21/06/2020. 


\section{Derechos de autor}

La revista Deusto Estudios Cooperativos es una revista de acceso abierto lo que significa que es de libre acceso en su integridad inmediatamente después de la publicación de cada número. Se permite su lectura, la búsqueda, descarga, distribución y reutilización legal en cualquier tipo de soporte sólo para fines no comerciales y según lo previsto por la ley; sin la previa autorización de la Editorial (Universidad de Deusto) o el autor, siempre que la obra original sea debidamente citada (número, año, páginas y DOI si procede) y cualquier cambio en el original esté claramente indicado.

\section{Copyright}

The Deusto Journal of Cooperative Studies is an Open Access journal which means that it is free for full and immediate access, reading, search, download, distribution, and lawful reuse in any medium only for non-commercial purposes, without prior permission from the Publisher or the author; provided the original work is properly cited and any changes to the original are clearly indicated. 